\title{
Kafkasya'nın Karadeniz Kıyısındaki Antik Buluntular
}

\section{K.A. Vladimirov \\ Çev. Didem Çatalkılıç}

En eski zamanlardan itibaren Karadeniz'in Kafkasya kıyıları antik uygarlıkların koloni ve ticaret yerleşimlerinin kurulduğu bir yer oldu. Buraya, Kolhis kıyılarına yarı mitolojik Argonotlar altın post için geldiler. Burada, denize inen Kafkas dağlarının ormanlık yamaçlarında Antik Yunanlılar ticaret kolonileri kurdular. Bu kolonilerin yıkıntıları üzerinde, uygar dünya merkezlerinden uzak bu ülkeye Hristiyan öğretisinin ışığını getiren Bizanslıların yeni yerleşimleri ortaya çıktı. Son olarak, kıyının sakin koylarında Cenevizliler tahkimli limanlarını inşa ettiler.

Kıyının tepelerinde ve teraslarında bir zamanlar, arkalarında burada olduklarına dair izler bırakan kültürlü halklar yerleşmişti.

Birçok yerde, Soçi ve Sohum şehirleri arasındaki bölgede, bugünkü Abhazya ve Megrelya'nın bir kısmında çok sayıda antik eser ve yıkılmış Hristiyan kiliselerinin kalıntıları bulundu.

Bir zamanlar canlı bir yaşamın olduğu yerleri kaplayan geçit vermez ormanlar ve çalılıklar, terk edilmiş şehirlerin ve kolonilerin unutulmuş yıkıntılarını dünyadan gizlediler...

\section{Antik Tarihçiler}

Antik tarihçilerin bilgilerine ve bugünkü araştırmalara göre, Karadeniz sahilinin bahsedilen bölgesinde, Sohum yakınlarındaki Gelencik nehri koyunda Milet kolonileri Torik ve Bata bulunuyordu. Fazis veya Rion nehri ağzındaki Fazis kolonisi antik Kolhis bölgesinde bulunuyordu. Dioskuriada veya Sevastopol (Gürcüce Sebast)

Drevnosti Çernomorskago poberejya Kavkaza, S.-Petersburg, 1900. (Makale gönderim tarihi: 06.10.2017, makale kabul tarihi: 08.10.2017).

** Didem Çatalkılıç, Ege Üniversitesi, TDAE, Türk Tarihi Anabilim dalı, Doktora Öğrencisi, İzmir. 
Karadeniz'in doğu sahilindeki en önemli Yunan kolonisiydi. Bu koloninin yeri konusu hala tartışmalıdır (Gürcü kaynağı bugünkü Sohum'u işaret eder). Dioskuriada Kodor ve İngur nehirleri arasındaki bölgeyi kaplayan cumhuriyetin metropolü kabul ediliyordu.

Dioskuriada Cumhuriyeti o kadar güçlüydü ki (Gürcü vakanüvisin sözlerine göre) Kral Farnoz'un Eguri bölgesine, yani Fazis (Rion) ve Kodor nehirleri arasında bulunan, cumhuriyetin hakimiyetinde olan bölgeye saldırısını püskürtmüştü. Muhtemelen burada basılmış olan, üzerinde Yunanca "Kolhida" ve "Dioskuriada" yazan sikkeler bu koloninin bağımsızlığını teyit ediyor. Bugünkü Abhazya, Megrelya, Gurya ve yukarı İmeretya bölgelerine dağılmış çok sayıdaki mimari anıt yüksek kültürel gelişmişliği göstermektedir. Bu anıtlar arasında özellikle, Sohum yakınlarında, Kelasur'da başlayarak uzak bir mesafeye uzanan ve Atangelo yakınlarında İngur nehrine dayanan siklopik duvar ilgi çekicidir. Uzunluğu 160 verste kadar varır ve yer yer kulelere sahiptir. M.S. II. yüzyılda yaşamış Ptolemaeus bu duvarı "sağlam duvar" olarak adlandırır. Dioskuriada iki ticari yola sahipti, birincisi Kodor nehri boyunca Kluhor geçidine doğru çıkıyor, sonra Teberda ve Kuban nehirleri boyunca aşağı iniyordu. Bu bölgede günümüzde de anıtların ve Hristiyan kiliselerinin pek çok kalıntısı bulunmaktadır. Diğeri ise Fazis nehri boyunca Kutais, Sarapanı (Gür. Şaraponi) üzerinden, Suram geçidinden geçerek Mtsheti'ye vd. uzanıyordu.

Dioskuriada ile komşu olarak Merkul nehrinde Gvenos ve Heraklia veya Anaklia kolonileri bulunuyordu.

Antik yazarların bilgilerine göre, Anapa'dan Gelencik'e kadar sahil şeridinde Kerketler yerleşmişlerdi. Heniohlar, Rion ağzında yaşayan Kolhlarla komşuydu. Strabon (M.Ö. 66 - M.S. 24) Zih (Gürc. Cik) kabilesine ve Soan ya da Svanlara işaret ediyor. Strabon Zihleri Heniohlar ve Aheyler arasına, Soanları ise Kolhların yukarısına yerleştiriyor. Abasklar veya Abhazlara ilk kez, M.S. II. yüzyılda yaşayan Arrian'ın eserinde rastlanır. Bizans tarihinde Abhazya yaklaşık M.S. 180 yılında tanınmaya başlamıştır. Kilise anlatılarına göre, bu ülkeye Hristiyanlığın ışı̆̆ını ilk kez havari Andrey getirmiştir. Yol arkadaşı Aziz Simeon Kenanit yerliler tarafından işkence edilerek öldürülmüş ve Anakopia'da (Gürc. Nikopsiy) defnedilmiştir. Naaşının üzerine kilise 
inşa edilmiştir. Burada şimdi Novıy Afon manastırı kuruludur. Bir söylenceye göre, Sohum'dan 12 verst uzaklıkta, Guma köyü yakınlarında, Gumısta nehri üzerinde yer alan yıkık bir kilisede Pitsunda'ya sürgün edilen Aziz İoann Zlatoust'un (Yannis Khrysostomos - ç.n.) naaşı 33 yıl boyunca kalmıştır.

Tarihçi Prokopius (d. M.S. 529) Abhazları Hristiyanlığa davet etti ve Bizans İmparatoru Justinyen'e (M.S. 527-566 ) onlar için Pitsunda'da Meryem Ana kilisesi inşa edilmesi çağrısı yaptı. Bugün Pitsunda'da bulunan kilisenin o olup olmadığı ya da yeniden inşa edilip edilmediği bilinmiyor.

Tüm bu bölgeye yayılmış antik anıtlar, görünüşe göre, tamamen unutuldu ve antik Hristiyan kiliseleri veya anıt mezarları geçit vermez ormanın ortasında ancak zamanla ve tesadüfen keşfediliyor.

\section{Poltavskoye Köyü}

1886 'da Sohum Okrugu'nda, Batı Maharka nehrinde bulunan Poltavskoye köyü yakınlarında, Sohum şehrinden 25 verst uzaklıkta, sık bir ormanda yerli halk tarafından tamamıyla korunmuş antik bir kilise bulundu. Kilisede eşya ve ayin aksesuarları insanların belki de birkaç yüzyıl önce terk ettikleri halde bulunmuştu. Imparatorluk Arkeoloji Komisyonu buluntuların korunması için derhal önlem aldı ve yerel yetkililerin doğrudan yardımıyla kilisedeki hemen hemen bütün buluntular toplandı ve kilise hakkında bazı bilgiler edinildi.

Antik kilisenin incelenmesi için başkan olarak Bay Bakradze görevlendirildi.

Buluntular arasında, karakteristik Gürcü süslemeleri ve Gürcü kilise harfleriyle yazılar olan bir tasvirden birkaç gümüş ve altın plaka vardı.

Bundan başka, bakırdan ajurlu yarım daire biçiminde bir tak bulundu. Birbirine perçinli dört parçadan oluşan bu tak yarım daire biçiminde yukarıya doğru sıralanmış dokuz deliğe sahiptir. Bu takın motiflerinde çift başlı kartal figürleri ve kalp biçiminde motifler birbirini tekrarlayan bir çizgi oluşturmaktadır.

Birkaç mum konulabilen bakır şamdanın gövdesi demir bir çubuğa oturtulmuş bakır parçalardan oluşmuştur. Şamdanın kaidesi üç dökme 
kabzayla sabitlenmiştir ve genişlemektedir. Anlaşılan mumun takıldığı çivili yukarı kısım, on iki parçalı etrafı bakır ajurdan oluşmaktadır.

Kase biçimindeki bakır buhurdanlık veya asılan lamba bakır telle örülmüş dallardan oluşan üç zincire sahiptir.

Yuvarlak ayaklı ve ayağın alt parçası kırık olan camdan yapılmış kase biçimindeki nesne, görünüşe göre şamdan veya lambadır.

Yukarıda sayılan nesneler dışında bu kilisede yıldız motifli bakır bir disk, son derece orijinal biçimli haçlar, farklı ölçülerde iki bakır kase, bir nesneyi destekleyen 4 sap, iki tabak, üç motifli ajurlu maşrapa, ortası delik 36 kase (herhalde şamdan için) ve farklı boyutlarda demir haçlar bulunmuştur.

Antik kilisenin kalıntıları asırlık ormanın içinde, yüksek bir yamaçta bulunmuştur. Kilisenin boyutları çok büyük değildir; önündeki avluyla birlikte 10 arşındır. Kilise düzensiz biçimli taşlardan inşa edilmiştir. Kilisenin etrafında taşlardan örülmüş yıkık bir duvar bulunmaktadır, bu taşlardaki yarıklardan şimdi dev porsuk ağaçları çıkmıştır.

Kilisenin içinde biri yazıyla bezenmiş, diğeri çok güzel süslü iki kare kireç taşı levha bulunmuştur. Kitabede "Aziz Feodor ${ }^{1}$, Mikael'i bağışla" yazmaktadır. Gürcülere ait kiliselerde kullanılan büyük harflerle yazılmış kitabe de bu kilisenin Aziz Feodor'a ithaf edildiğini göstermektedir. Levhalardan başka burada süslenmiş kırık taş parçaları ve oymalı sütün başlıklı birkaç kolon parçası bulunmuştur. Yıkıntının altında taşla örülmüş duvarları olan, küçük dikdörtgen bir tabut da bulunmuştur. Tabutta (14 verşok ${ }^{2}$ uzunlukta ve 7 verşok genişlikte) insan kemikleri ve iki at dişi bulunmuştur.

Bu kiliseden az uzakta, Voronov şehri sınırları yakınında aynı tipte diğer bir kilisenin yıkıntıları bulunmaktadır. Taştan yapılmış bu kilise 13 arşın uzunluğa 4,5 arşın genişliğe sahiptir.

Bölge sakinleri özel yapıları için yıkıntılardan yararlanmıştır, kilisede üzerleri heykel kaplı 2 kare levha ( 1 arşın ve 6 verşok karelerin ölçüleridir) bulunmuştur. Her levhanın ortasında niş tipinde ve derin bir kare çukur vardır ve her levhada kabartı bir tasvir yer almaktadır.

\footnotetext{
${ }^{1}$ Feodor - Theodore. (ç.n.)

${ }^{2}$ Verşok - 4.4 cm'ye karşılık gelen eski bir Rus ölçü birimi. (ç.n.)
} 
Nişin etrafındaki dört bölümde, İncil ve kilise tarihinin farklı konuları kabartmalarla geniş şekilde işlenmiştir. Figürler insan yüzleri dışında gayet açık yapılmıştır.

Birinci levhadaki nişte çocuklu Meryem Ana'nın kemerli figürü tasvir edilmiştir; bu figür üzerinde yukarı doğru yükselen iki yarım dairenin orta bölümünde perde takılmıştır. Yukarıdaki boşluklarda Aziz Georgi ve Aziz Dimitri yönetici sınıftan insanlarmış gibi tasvir edilmiştir. Aziz Georgi figürünün altında ezilen bir ejderha, Aziz Dimitri'nin altında ise yenilmiş bir erkek figürü vardır. Nişin her iki yanında dua eder konumda insan; yavrularını besleyen bir alageyik, ellerinde kilise maketi tutan iki figür ve başında yuvarlak şapkalı ve beli kemerli erkek figürü görülmektedir. Ayrıca burada bir kısmı kırık kartal başı görülmektedir.

İkinci levhadaki nişte çarmıha gerilmiş İsa Mesih figürü kabartı tasviri bulunmaktadır. Bu tasvirde Kurtarıcı uzun chlamys ${ }^{3}$ giymiştir; bu kıyafetle erken Hristiyanlık döneminde tasvir edilmiştir. Çarmıhın yan tarafında Meryem Ana ve Yuhanna tasvirleri, arkalarında ise pantolonları dizlerine kadar sıvanmış ve elleri bağlı iki haydut tasvir edilmiştir. İsa'nın başı üzerinde haçın bağlantı yerinin altından aşağıya doğru sarkan eli görülmektedir. Haçın bağlantı yerinin üzerinde ise galiba Tanrı baba figürü yer almaktadır. Diğer alanlarda şu gruplar görülmektedir: Ağlayan Havari Petrus yüzünü elleriyle kapamış bir şekilde durmaktadır. Önündeki dallarda bir horoz yer almaktadır. Burada Petrus baş aşağı çarmıha gerilmiş, iki asker onu bacaklarından haça bağlamışlardır.

Haç altında, nişte, Kurtarıcı'nın diriliş görüntüsü görülmektedir. Sağda mezar taşında ellerini ileriye doğru uzatmış i̇sa oturmaktadır. Onun önünde ise ellerinde testi tutan iki figür yer almaktadır. Solda ise yerde mızrak ve yuvarlak kalkan tutan yenilmiş üç asker figürü görülmektedir. Yandaki figürlerden birinde Kurtarıcı'nın vaftizi tasvir edilmiştir. Mesih uzun saçlı ve çıplaktır. Sağında Mesih'in başına sağ elini koyan, haç taşıyan çıplak Hz. Yahya yer almaktadır. Üzerlerinde güvercin görünümünde Kutsal Ruh ve iki melek yer almaktadır. Burada

\footnotetext{
${ }^{3}$ Yunan erkek halk giysisi (ç.n.).
} 
yine koşumları takılmış bir eşeği götüren bir insan figürü vardır. Yukarıda kurban etmek için oğlunun elinden tutan Ibrahim, solda boynuzundan çalıya bağlanmış koç figürü yer almaktadır. Alttaki levhada ava çıkmış bir binici tasvir edilmiştir. Zengin koşumlu bir atın üzerinde oturan binici, bir elinde gerilmiş bir yay tutmakta ve diğer eliyle de ileriyi işaret etmektedir. Sol yanında, omuz kayışında kılıç bulunmaktadır. Atlının önünde geriye doğru bakan bir geyik görülmektedir. Geyiğin üzerine bir av köpeği atılmaktadır ve yanında ellerini yukarı kaldırmış, başının üzerinde haç olan uzun giysili bir insan figürü görülmektedir. Yine onun yanında, elleri yukarıda küçük bir insan figürü ve testinin üzerinde beş çiçekli bir maşrapa bulunmaktadır.

Levha tasvirinin dışında çok sayıda süslemeli taş, tasvirli oymalı sütunlardan geriye kalan iki sütun başlığı bulunmuştur. Bu sütun başlıklarından birinde birbirleriyle çarpışan iki koç tasviri, diğerinde ise insanı yutan ağzı açık bir ejderha tasviri yer almaktadır. İnsanın sadece el ve ayakları gözükmektedir. Poltavskoye köyü yakınında tamamen aynı formda bir bakır haç ve bir arşın derinlikte, bitki kökleri tarafından parçalanmış bir parça beyaz balmumu bulunmuştur. Hiçbir yerde yazıt bulunamamıştır.

Poltavskoye köyü yakınlarındaki antik kilisede bulunan antik ikonlardan gümüş yaldızlı madeni kaplama parçaları, uzun çalışmalardan sonra, çevrelerindeki birkaç küçük madalyonla birlikte Aziz Katerina ve Hz. Yahya'nın (Vaftizci Johann) çehrelerine ait iki işlemeli ikon kapağı halinde toplanabilmiştir. Madeni kaplamalar zarif ve çok ince işlenmiştir, üzerlerinde kilise alfabesinin harfleriyle yazılmış Gürcüce kitabeler bulunmuştur. Aziz Katerina'nın ikonunda "Aziz Katerina, Meryem'in ruhunun koruyucusu ol" yazılıdır, $\mathrm{Hz}$. Yahya'nın ikonunda ise “.... Söyle, vaiz, İsa'nın tövbesiyle maruf büyük vaftizcisi, tövbenin bayraktarı olan vaiz."

Küçük ayrı bir parçada ise "iloryalı Aziz Georgi” yazılıdır.

Gerek madeni kaplamaların gerekse işlemeli taşların kökeni hiçbir yerde gösterilmemiştir. Fakat Bay Bakradze madeni kaplamalardaki ve levhalardaki paleografik yazı karakterine bakarak M.S. 11. yüzyıla ait olduklarını düşünmektedir. Olginski köyü yakınındaki tapınakta, 
Voronov arazisinde yer alan kilisenin ve Dranda manastırının (bkz. aşağıda) yakınında bulunan motifli taşlar daha erken bir döneme aittir.

$\mathrm{Bu}$ levhaların sonraları Yunan kilisesinin ikonostastan geliştirilen sunak setlerinin parçası olduğu şüphesizdir. Cennet kapılı benzeri alçak sunak setleri özellikle antik Hristiyan kiliselerinin karakteristik çizgileridir ve Gürcistan'ın birçok antik kilisesinde bugün bile mevcuttur.

Kilise tarihinden konuları işleyen, son derece ince işçilikle yapılmış kabartılı taş levhalardan oluşan sunak setlerinin Tsebelda'nın pek küçük antik kilisesinde bulunmuş olması oldukça ilginçtir. Fransız seyyah ve araştırmacı Frederic Dubois de Montperreux'nin (Voyage autour du Caucase) işçiliğine hayran kaldığı Ahaltsı'taki uyezdindeki Sapara manastırının eski kilisesinde yer alan ünlü sunak setinin benzeridir.

Poltavskoye köyündeki kilisede bulunan perçinlemiş dört parçadan oluşan bakır kemer, görünüşe göre, sunağın cennet kapısı üzerinde ark görevi görmüştür ve girişin iki yanında duran iki kolonu birbirine bağlamıştır, bu kolonların kalıntıları harabelerde bulunmuştur.

Olginski köyü çevresindeki gür ormanın ortasında küçük bir kilisenin yıkıntıları da bulunmuştur. Kilisenin etrafındaki küçük alan, yılda bir kez kilisenin yıkıntılarında dua edildiği için temizlenirdi. Kilisenin duvarları sadece bir sajen ${ }^{4}$ kadar korunmuştur. Kilisenin ölçüleri çok büyük değildir; 8 arşın genişlikte ve 13 arşın uzunluktadır.

Duvarlar iyi yontulmuş taşla kaplanmış, sıvalar dökülmüştür. Sunaktaki taht duvara bitişik dört köşeli kalın taş tabanlı tek parça levhadan yapılmıştır. Burada bulunan birkaç figürlü levhadan özellikle ikisi ilginçtir. Birinci parçada Yunan ayin kıyafeti giymiş, dua eden bir din adamının kabartılı tasviri yer almaktadır. Kıyafetin üzerinde Gürcü kilise harfli bir kitabe yer almaktadır, fakat bu yazı çözülememiştir. Din adamının yanında iki figür yer almaktadır. Biri elinde buhurdanlıkla cüppe giymiş din adamını, diğeri de muhtemelen büyük melek Cebrail'i temsil etmektedir. İkinci parça kabartma süvari tasviriyle

\footnotetext{
${ }^{4}$ Sajen - 2.13 metreye karşılık gelen eski bir Rus ölçü birimi. (ç.n.)
} 
işlenmiştir. Bu tasvir özellikle temiz ve düzenli bir şekilde yapılmıştır. At koşumlu olarak tasvir edilmiştir, fakat atın kafası ne yazık ki kırılmıştır. Binici kısa kaftanlı ve iki parçalı tokadan oluşan kemerle temsil edilmiştir (günümüzde Kafkasya'da taşınan kemer tipinde). Kemerde kılıç takma yeri vardır ve kılıç yoktur. Süvari ileriye eğilmiş şekilde oturmaktadır. Sağ eliyle beş haleli küçük bir haçlı bayrak direğini, sol eliyle de dizgini tutmaktadır. Atın başında zengin süslemeli bir koşum takılıdır. Kuyruğu örülüdür ve küçük örgüler bırakılmıştır.

Levha parçalarından başka, burada Poltavskoye kilisesi yıkıntılarında bulunan yemek tabağına benzer kırık bir bakır yemek tabağı da bulunmuştur.

\section{Dranda}

Dranda manastırı yakınlarındaki küçük Hristiyan kilisesinin kalıntılarında da iki taş heykel kalıntıları ve eski bir tas bulunmuştur.

Parçalardan birinde oyma başlıklı kolonda çift oklu kemer tasvir edilmiştir. Mesih tahtta oturur şekilde, haç halesi içinde tasvir edilmiştir. Sağ eliyle Yunan tarzı takdis etmekte, sol eliyle de İncil'i tutmaktadır. Kolonun arkasında, Mesih'in önünde dua eder gibi ellerini ona uzatmış bir kadın durmaktadır. İkinci parçadaki figürler ve kâse incelenmemiştir.

\section{Sohum}

1886 yılının ekim ayında, Sohum'a 12 verst uzaklıkta, Kelasuri nehrinin sağ kıyısında yıkılmış iki küçük kilise bulunmuştur. Albay Tsilossani tarafından yapılan kazıda Poltavskoye köyündeki kilisede bulunanlara oldukça benzer birkaç bakır nesne çıkarılmıştır. Kiliselerden birinde, tahtın altındaki yerde dört kollu demir haç bulunmuştur. Sonra, ortası çivili birkaç bakır mumluk, gümüş yaldız kaplamalı bir parça, Gürcü kilise harfli ikonlardan oluşan ikon kapağı parçaları ve renkli cam parçaları bulunmuştur. Burada Latince kitabenin belirgin olduğu kırık bakır çanın üç parçası da bulunmuştur. Formda ve kitabede yer alan çan, Svanetya'da Bay Bakradze tarafından görülen birkaç antik çandan birine benzemektedir. 
Adı geçen kiliselerden başka, son zamanlarda araştırılan bazı yıkıntı ve mağaralar Bay Çernyavski ve Albay Vvedenski tarafından araştırılmış ve tasvir edilmiştir. Bunlarla birlikte Sohum çevresindeki bakir ormanlarda var olan çok sayıda eseri de zikretmişlerdir. Bu şekilde Pitsunda kilisesinden 15 verst uzaklıkta, Bzıb nehri havzasındaki dağlarda bulunan antik manastırın kalıntıları da öğrenilmiştir. Bu kalıntılarda, Abhazların bilmediği bir malzemeden yapılmış rulolar vardır. Bay Çernyavski bu kalıntıların ünlü Pitsunda patrikliğinin antik kütüphanesinin kalıntıları olduğunu düşünmektedir. Hacalabey adıyla bilinen bu kalıntılar günümüzde bitkilerle kaplanmıştır ve bu yüzden dış görünüşleri hakkında bir fikir edinmek mümkün değildir. Kalıntılar sadece uzaktaki Pitsunda kilisesinden görülebilir. Menkıbelere dayanarak, bunun Pitsunda'dan gelen Abhaz papazın unutulmuş yazlık evi olduğunu varsayabiliriz.

Psırtsha nehrinde, Sohum'dan 20 verst uzaklıkta, Aziz Simon Zealot adına yapılmış antik Bizans kilisesi kurulmuştur. Şu anda kilise Novıy Afon manastırının keşişleri tarafından ayakta tutulmaktadır.

Bir manastır binasının yapımı ve tadilatı sırasında süslemeli ve Yunanca yazıtlı son derece ilgi çekici birkaç taş bulunmuştur. Dağların doruklarında kocaman bir duvar ve birkaç kule yıkıntısı da bulunmuştur. Dubois'e göre, bu antik Trakhea kalıntıları Prokopius tarafından tasvir edilmiştir.

Albay Vvedenski'ye göre, deniz kıyısında duvar kalıntıları bulunmaktadır. Bu kalıntıların izleri kıyıdan çok uzakta denizden bile görülmektedir. Yine o Huap mevkiindeki antik lahitleri işaret etmektedir. Üç lahiti 1869 yılında kendisi bizzat kazarak bulmuştur ve birinden toprak fincan, altın kanca ve altın menteşe ile demir keser çıkarmıştır. Bu eşyalar sonradan Kutais'e taşınan eski Sohum müzesine teslim edilmiştir.

Sohum şehrinde yer yer büyük bir ihtimalle DioskuriadaSevastopol olan eski şehrin izleri görülmektedir. Bunların yanı sıra burada erzak dükkanının yakınlarında oldukça geniş bir yükselti de bilinmektedir. Bu tepenin civarında deniz içinde devam eden büyük duvarın kalıntıları ve eski kalenin kuleleri görülmektedir. Gümrüğün karşısında bir kısmı denizin dibinde görülebilen bir kısmı ise alüvyonlu toprakla örtülmüş antik duvar kalıntıları hala seçilebilmektedir. 
Duvarlar arasında günümüzde kumla dolu olan "Yunan kuyusu" hala bilinmektedir.

Sahil bulvarına paralel olarak antik rıhtımın izleri görülmektedir ve Bay Vvedenski'ye göre antik madeni para ve eşyaların bulunması da sürekli bir ticaretin olduğunu ortaya koymaktadır. Güçlü bir dalga kıyıdaki kumu ve taşları hareket ettirdiğinde ve kıyının bir bölümünü yıkadığında insanlar kıyıya akın ederler ve kumu elleriyle kazarak pek çok değerli nesne bulurlar. 1868 'de iki işçi bu şekilde altın tacı buldular. Albay Vvedenski'nin buluntuları "kaz tüyü kalınlığında sarkıntıları olan yuvarlak altın çember" olarak adlandırdığını belirtmek gerekir. "Kavkazskoye obozreniye" (23-24 Aralık 1886 - 25 Ocak 1887) gazetesinin muhabirine göre, aynı yerde, deniz dalgalarının aşındırdığı eski temellerde yüzden fazla altın ve Roma imparatorunun tasvir edildiği gümüş ve bakır paralar bulundu.

Lağvedilen Sohum kalesi yakınlarında, denizin 1 arşın derinliğinde suyla yıkanmış ilginç çıkıntıları olan antik taş duvarların izleri görülebilmektedir. Kalenin ortasında (şehirden 7 verst uzaklıkta) ilginç yapısıyla dikkat çeken "Antik Sohum" harabelerinin kalıntıları Sohum burnunun batıya doğru olan alt kıyısında da yer almaktadır.

Oval kurgan Sohum şehrinin ardındaki Samato dağının yamacında bulunmaktadır. (Belki de Gürcüce "sagmto" - kutsal veya "satema" toplumsal kelimesinden gelmektedir.)

Ayrıca aynı dağın sırt kısmında sert kum taşında ustaca oyulmuş antik mağara dizisi bilinmektedir. Bu mağaraların bir kısmı Bay Çernyavski tarafından toprak tabakasının çökmesiyle bulunmuştur. Çökmeyle öndeki odaların çoğu toprakla dolmuş ve bu odalarda çapı 6 verşok uzunluğunda borular ve yukarıya doğru oval formda gelişen pencere ve kapılar ortaya çıkmıştır.

Sohum şehrinden beş verst uzaklıktaki vadinin derinliğinde, yüksek bir terasta iki antik kale bulunmaktadır. Ark şeklinde köşeli çakıl taşından yapılmış eski bir köprü harabelere gitmektedir. Kalelerden biri iki katlıdır, birkaç odaya bölünmüştür ve kaleye kayaya oyulmuş patikadan gidilmektedir. Nehirdeki yaya köprüsünün izleri gözle görülmektedir. Burada ise çok derin ve ikiye ayrılan alçak bir mağara görülmektedir. Belsi nehrinin yatağında kireçli kayaya oyulmuş güzel yolun iki kesiti de görülmektedir. 
Sohum şehrinin ardındaki üç tepede antik bina ve temelinin kalıntıları görülebilir.

Sohum'un 35 verst güneydoğusunda, deniz kıyısındaki küçük bir tepede, girişi olamayan eğik duvarlı büyük kare "Satamaşo" (Gürcüce 'eğlence yeri') kalesinin kalıntıları korunmuştur. Bu kale yanlış bir şekilde pek çok araştırmacı tarafından antik Dioskuriada'nın kalıntıları olarak kabul edilmiştir.

Sohum'dan 15 verst uzaklıktaki Kelasur ve Besla nehirleri arasındaki su ayrım çizgisinde bazı antik yapıların izleri, kurumuş derin su kuyuları ile maden posası ve yanmış maden posası yığınları görülmektedir. Gümüş-kurşun madeni yatakları açısından zengin olan bu yerlerde, eski maden ocakları ve onları işlemek için atölyeler bulunuyor olabilir.

Sohum'un 25 verst güneydoğusunda, Arrianus'un haritasında adı geçen antik Roma şehrinin kalıntıları bulunmaktadır.

Sohum'dan 18 verst uzaklıkta, Gvaldza köyünde antik lahitler görülmektedir. Benzer lahitler Ahabiuk dağı yakınlarındaki terasta, Guma köyünde de bulunmuştur.

Kelasur nehrinin kaynağından 8 verst uzaklıkta birkaç eski kule ve eski duvarlar bulunmaktadır. Benzer şekilde kuleler onlardan 6 verst uzaklıkta bulunmuştur. Bu 7 kule Tsebelda'ya giden Macara nehri boğazını kapatmaktadır.

Abhazya dağlarının hemen hemen ulaşıımaz olan ormanlarının derinliklerindeki antik kilise, kale, lahit v.d. kalıntıları bilinmektedir. Bunların yanı sıra, özellikle dikkat çekicidir, Sohum şehrinden 50 verst uzaklıkta (yaklaşık 20 verst düz çizgi halinde), Aytsera boğazında, Bizans kilisesinin daha antik temeline bitişik ve Nart kahramanı Sosruko'nun taş mezarı bulunan güzel bir kale vardır. Dağlara daha uzak, ana sıra dağların eteğine kadar ve dağın kuzey yamacındaki Kluhor dağ geçidinden daha uzakta antik kuleler, kaleler ve devlerin (Abhazca adau) evi görülmektedir. Her biri hakkında fantastik olaylarla süslü özgün efsaneler vardır.

Eski Gagra istihkamının altında büyük bir yeraltı zindanı ve görenlerin anlattıklarına göre, iki ucunda kilitli kapılar olan bütün bir koridor ağı vardır. Oradan kazılıp çıkartılan hazineler hakkında bir efsane mevcuttur. 
Gagra yakınlarındaki dik kayada iki sajen yükseklikte bir mağara daha bilinmektedir. Bu mağaranın oval kapısı başka bir yerden getirilmiş taşlarla yapılmıştır ve görünüşe göre kimse onu incelememiştir.

Sohum'dan 8 verst uzaklıkta, Ahabiuk dağında sarkıtlı bir mağara bulunmuştur. Bay Çernyavski bu mağarada günümüzdeki insanların da bildiği ölmüş pek çok memeli tipinin kemik koleksiyonunu bulmuştur. Çernyavski'nin bulduğu iki insan kemiğinden biri taşlaşmıştı ve bir parça kireç taşı barındırıyordu. Az uzaktaki komşu dağın yamaçlarında bol miktarda fosilleşmiş deniz kestanesi ve kabukları vardı. Aynı dağın kuzey yamacında dev bir mağara bulunuyordu.

Dereden geçince, Ahabiuk dağının karşısında, farklı görünüşteki balıkların kireçli tabakada zengin izleriyle dolu, yarıya kadar toprağa gömülü bir mağara görünmektedir. Benzer mağaralara Sohum'un 6 verst uzağında, Abıdza dağının kuzeydoğu eteklerinde de rastlanmaktadır.

Sohum çevresinde, hatta şehrin içinde, Macara nehri boğazındaki yolun yanında ve Abıdza dağının yamaçlarında, Gumısta nehrinde çok sayıda ilginç mağaralar bilinmektedir.

Cigetya ve Abhazya dağ çukurluklarında göl dönemi insan yapısı izler bulunmuştur. Belki de burada, Kafkas ötesinin Gökçe (Sevan ç.n.) ve Toparavan göllerindeki gibi kazıklı evlerin izleri bulunacaktır.

\section{Pitsunda}

Pitsunda yakınlarında antik Pitiunt şehrinin kalıntılarının 30 verstlik bir dairede olduğunu Strabon söylemektedir. Bu kalıntılara dair bilgiler Dubois'de de vardır.

Pitsunda'dan 15 verst uzaklıkta, Bzıb (Mıçiş) nehrinin kolu üzerinde sarp kayada bir mağara manastırı bilinmektedir. Girişinin üst tarafında bir pencere yer almaktadır. Albay Vvedenski'ye göre bu manastırın bodrum katı 22 hücreden oluşmaktadır. 1878 yılııın Mayıs ayında onun emriyle incelenen hücrelerden birinde gümüş kaşık, iki toprak çömlek ve metalden yapılmış üç küçük çubuk bulunmuştur. Hücrelerin üst katlarında kalanlar incelenmemiştir. 


\section{Gudauta}

Gudauta köyünün kuzeyinde, denizin yukarısında, Dubois'in seyahatinden kısa zaman önce depremden zarar görmüş Solagu adlı eski manastır bulunmaktadır. Gudauta limanının karşısında, Bay Çernyavski'nin sözlerine göre, su altında bir taş levhanın çıkıntıları olan taşlar bilinmektedir. Büyük ihtimalle bular kıyı yapılarının antik duvar kalıntılarıdır.

Dudriniş dağının zirvesinde (Sohum yakınlarında), herhalde kurban töreni için kullanılmış çok sayıda ok ve mızrak bulunmuştur.

Ana sıradağlardan geçen eski Roma yolunun ve Abhazya'nın günümüzde de ulaşılması zor Aytsera, Aykvara ve diğer boğazlarından geçen yollarının izleri hala fark edilmektedir.

Antik anıtların bulundukları yerler hakkında verilen bu bilgiler, yerli ahalinin sözlü hikâyelerinden başlayarak antik ve çağdaş bilim adamlarının ve amatör arkeologların değerli araştırmalarına kadar her türlü kaynaktan derlenmiştir.

Yukarıda söylenenlerden hareketle şöyle bir sonuca varılabilir: Karadeniz'in bütün Kafkasya kıyıları günümüzde bile incelemek için zengin bir bölgedir ve titiz araştırmalarla onu inceleyecek, geçmişte canlı olan bu yörenin eski yaşamını, zenginliğini ve bütün lüksünü parlak çizgileriyle ortaya koyacak tecrübeli bir arkeoloğu beklemektedir. 
